\title{
Application of GPS in Crustal Deformation Studies: A Case Studies in Mishmi Block of North Eastern India
}

\author{
${ }^{1}$ Laishram Sunil Singh, ${ }^{1}$ Arun Kumar and ${ }^{2}$ Okram Pratap Singh \\ ${ }^{1}$ Department of Earth Sciences, Manipur University Canchipur, Imphal, India \\ ${ }^{2}$ Department of Geology, Waikhom Mani Girl's College, Thoubal, India
}

\begin{abstract}
In our country Global Positioning System (GPS) now a days has its application in various fields namely the aircraft and ship navigation, surveying of crustal deformation, cadastral mapping, creation of GIS database and many other monitoring works. The North Eastern part of India is known to be one of the most seismically active regions of the world. Thus, the area is prone to natural calamities like earthquakes which lead to the crustal deformation in the region. A brief description of GPS permanent continuously monitoring station in Mishmi Block of North Eastern India, data processing and analysis and result as a case studies are presented in this study.
\end{abstract}

Key words: GPS, crustal deformation, Indo Myanmar Arc (IMR), Mishmi Block, monitoring, cadastral

\section{INTRODUCTION}

The Global Positioning System (GPS) is a space based navigation system, consisting of a constellation of 24 satellites, in six orbital planes with $55^{\circ}$ inclination to the equator. The satellites are placed at a height of about $20,200 \mathrm{~km}$ with $12 \mathrm{~h}$ orbital period and operated by the United States Department of Defense (DOD) for accurate determination of position, velocity and time. All the GPS satellites are controlled by system tracking stations, ground antennae and the master control station.

Crustal deformation studies have received new impetus all over the world with the full complement of satellites for adequate coverage, availability of comparatively low-cost receivers, sophisticated post processing softwares and international cooperation through International GPS Services for Geodynamics (IGS). In many countries the receivers are used permanently in a network mode with data telemetered and processed continuously to have upgraded baseline vectors regularly. For the past few years, regional GPS networks designed mainly to monitor strain for earthquake research and forecasting have been operated in many countries all over the world and have proved useful in detecting the crustal displacements.

\section{MATERIALS AND METHODS}

GPS measurements for crustal deformation studies have been made in campaign mode in southeast China, SE Asia covering Brunei, Indonesia, Malaysia, Philippines,

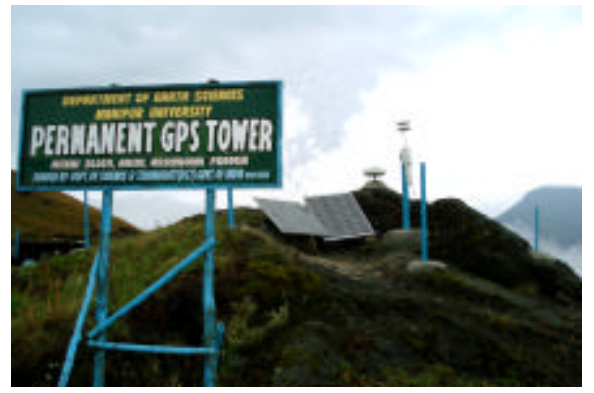

Fig. 1: GPS permanent station at Anini, Mishmi Block

Singapore, Thailand and Vietnam under the Geodynamics of South and South-East Asia (GEODYSSEA) project. Similar measurements have been made in Myanmar to infer the present-day crustal deformation around the sagaing fault system in Central Myanmar. Since, there are no campaigns mode GPS observations from NE India across the Indo Myanmar Arc, the actual geodynamic process of occurring in the region is poorly known. In order to understand the earthquake occurrence process and assess the future seismic hazards near the plate boundary in the region different permanent GPS station has been established. A brief description of one of the GPS permanent station, i.e., Anini in the Mishmi Block of North Eastern India, data processing and analysis and result as a case studies are presented in this study.

GPS site, data processing and analysis: The continuously operating GPS permanent station at Anini, Mishmi Block (Fig. 1) was installed in 


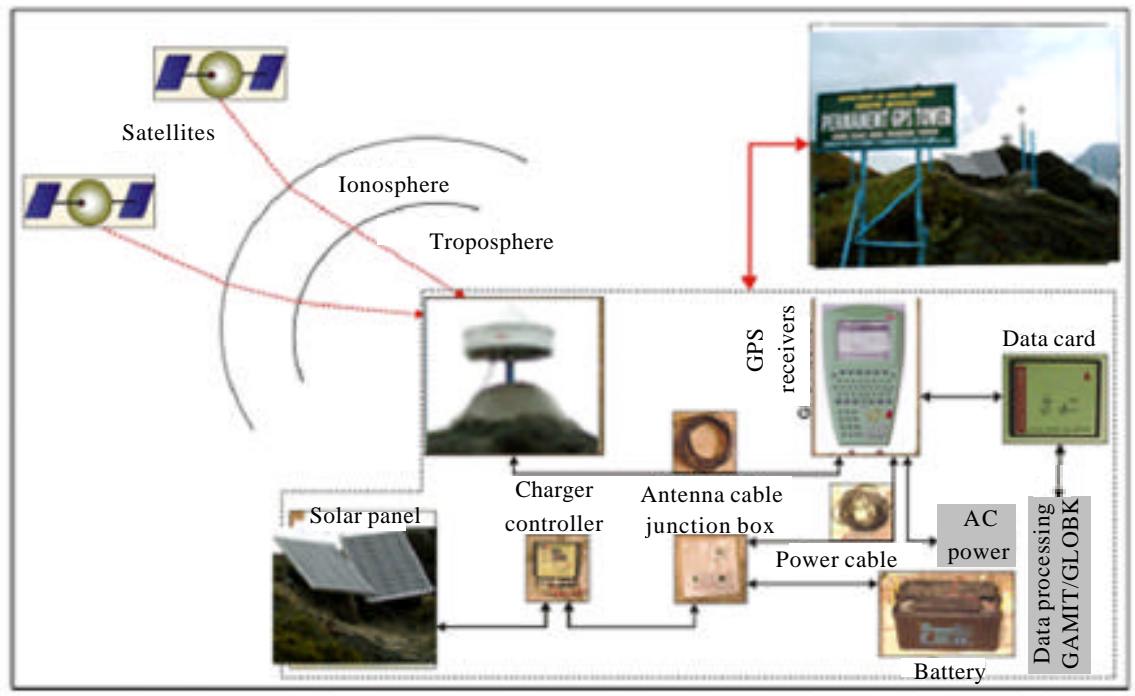

Fig. 2: Schematic representation of GPS permanent station, GPS instrument and its associated flowchart

2007. The station is located on a hill within the campus of A Coy 98 Bn Indo Tibetan Boarder Police, Anini.

The station is located on an outcropping of Mishmi Block. It is equipped with a Leica 1200 receiver and a Leica choke ring antenna. The antenna is fixed on an outcrop and cemented, the receiver and battery are housed in a small nearby shed. The receiver is powered by the $\mathrm{AC}$ as well as through batteries which are charged using the solar panels (Fig. 2). Operational from May 2007.

The GPS data obtained from the site have been converted into RINEX observation files and quality check was performed using TEQC (Translation, Editing and Quality Checking Software). The quality check plots of all the GPS data were carefully examined and the data with high cycle clips, multipath and of duration with $<18 \mathrm{~h}$ observation were removed from the analysis.

The processing of the GPS data from station is routinely performed at Department of Earth Sciences Manipur University using the GAMIT/GLOBK Software (Herring et al., 2010a, b). Data from IGS (International GPS Service) sites, namely, BAHR, ПSC, HYDE, LHAS, KIT3, KUNM and POL2. These data were processed on daily basis producing loosely constrained station coordinates and satellite orbits. These were further combined with loosely constrained solutions of globally distributed nearby IGS station data available from the Scripps Orbital and Positioning Analysis Centre (SOPAC; http:garner.ucsd.edu). Using the GLOBK Software (Herring et al., 2002), position estimates and velocity stabilization in ITRF08 were achieved.

\section{RESULTS AND DISCUSSION}

Time series 2008-2014 of anin site is shown in Fig. 3. In the time series North component shows deformation $8.9 \pm 0.5 \mathrm{~mm} /$ year, East component shows deformation $44.3 \pm 0.5 \mathrm{~mm} /$ year. In ITRF2008 reference frame the ANIN site shows a velocity of $45.1 \mathrm{~mm} /$ year towards $\mathrm{N} 78.6^{\circ}$, in reference to Eurasian plate it shows a velocity of $20.3 \mathrm{~mm} /$ year towards the $\mathrm{N} 50.3^{\circ}$ (Fig. 4) and in the reference frame of Indian it shows a velocity of $31.3 \mathrm{~mm} /$ year towards the $\mathrm{N}-9.4^{\circ}$.

The average resultant vector in ITRF 2008 from all the campaign stations (Singh et al., 2014) well distributed in Eastern Himalayan syntaxis shows the average for all the sites is $44.13 \mathrm{~mm} /$ year with and azimuth of $77.03^{\circ} \mathrm{N}$. It indicates the simmering tectonic stresses in a clock wise direction which may be one of the tell-tale evidences for a damaging future earthquake around EHS.

Mishmi Block in the EHS seems to be of very slow crustal velocity comparing to the neighbouring regions such as Tibetan Plateau, North and South China and Burmese Arc Region. We have compared the GPS results from this region and made an attempt for the first time for our investigated EHS which is indentor corner of the Eastern Himalayan terrain. The progressive deformation related to the anti-clock wise rotation of the Indian plate resulted the recent under thrusting of the Brahmaputra alluvium along the MT and the recent deformation along the Northern splays of the N-S trending dextral Sagaing strike-slip fault along which the Indian plate has moved towards North relative to the South China. It is inferred 

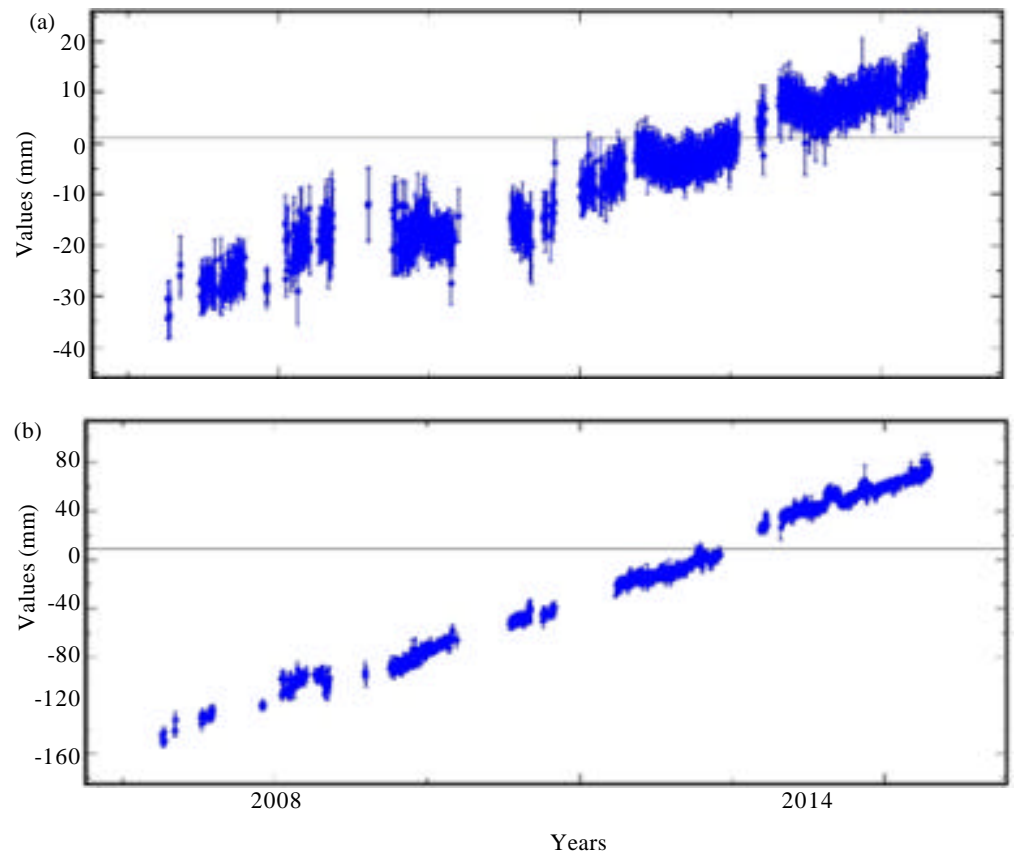

Fig. 3: Time series at anin in ITRF 2008: a) North component ( $8.9 \pm 0.5 \mathrm{~mm} /$ year) and b) East component ( $44.3 \pm 0.5 \mathrm{~mm} /$ year)

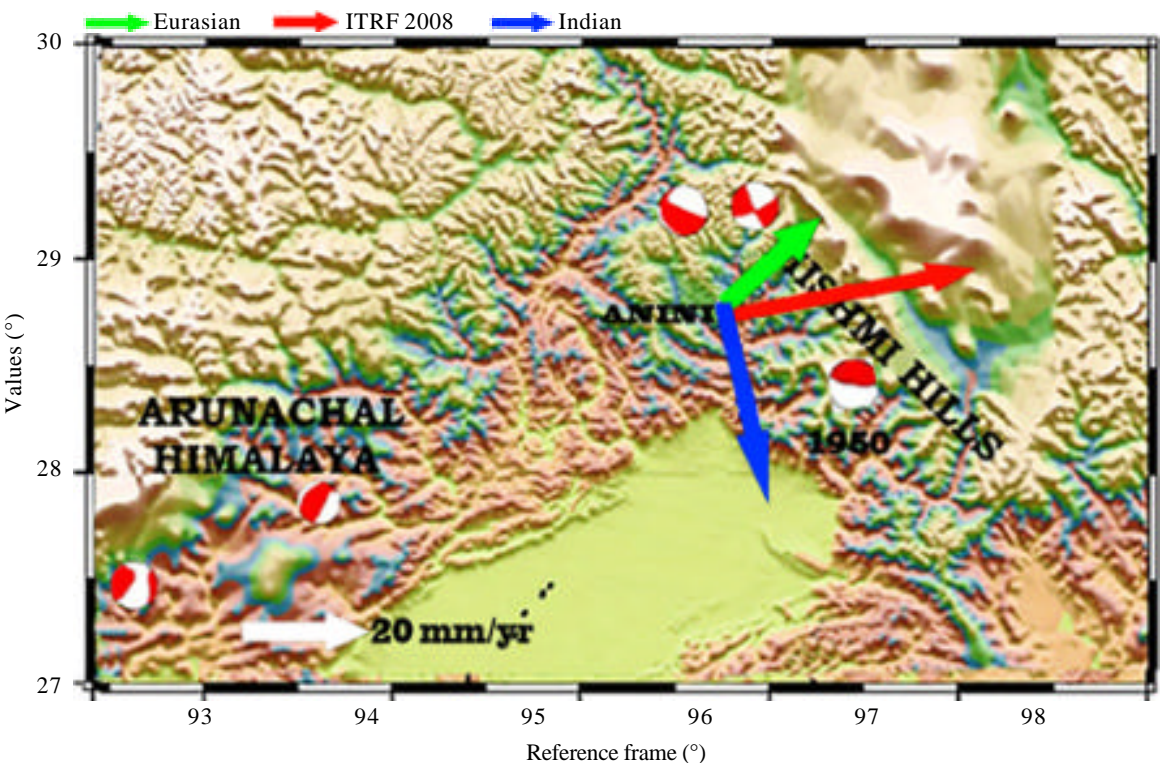

Fig. 4: Velocity vector plot with respect to Eurasian, ITRF2008 and Indian for Mishmi permanent GPS station, Arunachal Pradesh

that the recent uplift of the high-grade basement rocks along the Namche Barwa syntaxis or the EHS has developed the gravity collapse related steep normal faults along the mountain frontal part of the North Eastern Himalaya, Arunachal Pradesh. Thus the active tectonics seems to be associated with the later deformation that penetrated within the Indian plate from the tectonic deformation distributed along the margins of the Indian, South China and Indo-Burmese plates including, the recent uplift of the Eastern Himalayan syntaxis.

The measured velocity for the permanent GPS station of Mishmi Block is $45.1 \mathrm{~mm} /$ year towards $78.6^{\circ} \mathrm{N}$, Azimuth using the reference frame ITRF 2008. There is difference of velocity of Mishmi Block in comparison with the Indian 
plate. It indicates that Buttress between Himalayan Indo Myanmar Arc moves towards the North consistently.

If the velocity at Imphal is taken into consideration, it is $36.3 \mathrm{~mm} /$ year with azimuth of $55^{\circ} \mathrm{N}$ (Singh et al., $2014 a, b)$. The plate motion as per the results obtained from the last 5 years indicates that the subduction process is continued along with IMR.

\section{CONCLUSION}

GPS measurements across the frontal EHS provide important insight into the characteristics of continental kinematics between the India and Eurasia in the region where there is a large data gap. These measurements suggest that the frontal EHS accommodates about at least $20 \pm 4 \mathrm{~mm} /$ year of oblique convergence between the India and Eurasia plates. The detachment appears to be locked and accumulating strain for future earthquake.

\section{ACKNOWLEDGEMENT}

Financial assistance provided by Ministry of Earth Sciences and Ministry of Science and Technology Government of India to carry out the present investigations is thankfully acknowledged.

\section{REFERENCES}

Herring, T.A., R.W. King and S.C. McClusky, 2002. GLOBK: Global kalman filter VLBI and GPS analysis program Version 10.0. Master Thesis, Massachusetts Institute of Technology, Cambridge, Massachusetts.

Herring, T.A., R.W. King and S.C. McClusky, 2010a. GAMIT reference manual: GPS Analysis at MIT, Release 10.4. Master Thesis, Massachusetts Institute of Technology, Cambridge, Massachusetts.

Herring, T.A., R.W. King and S.C. McClusky, 2010 b. GLOBK: Global kalman filter VLBI and GPS analysis program version 10.4. Master Thesis, Massachusetts Institute of Technology, Cambridge, Massachusetts.

Singh, L.S., V.K. Gahalaut and A. Kumar, 2014b. Nine years of GPS measurements of crustal deformation at Imphal, Indo-Burmese wedge. J. Geol. Soc. India, 83: 513-516.

Singh, M.D., B. Kundu, J. Catherine, A. Kumar and V.K. Gahalaut, 2014a. First GPS results of crustal deformation across the frontal Eastern Himalayan Syntaxis and seismic hazard assessment. Bulletin of the Seismological Society of America (BSSA), America. 